Check for updates

Cite this: RSC Adv., 2018, 8, 13686

Received 27th February 2018

Accepted 29th March 2018

DOI: 10.1039/c8ra01723a

rsc.li/rsc-advances

\section{Production of renewable long-chained cycloalkanes from biomass-derived furfurals and cyclic ketones $\uparrow$}

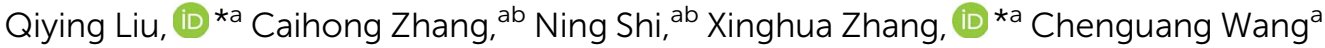 \\ and Longlong $\mathrm{Ma}^{\mathrm{a}}$
}

Developing renewable long-chain cycloalkanes from lignocellulosic biomass is of significance because it offers huge resource storage, wide applications in aviation/diesel fuels and mitigation of $\mathrm{CO}_{2}$ emissions. In this paper, cycloalkanes with carbon chain lengths of 13-18 were produced from biomass-derived furfural species (furfural and 5-hydroxymethylfurfural) and cyclic ketones (cyclopentanone and cyclohexanone) via aldol condensation, followed by hydrogenation to saturate the $\mathrm{C}=\mathrm{C}$ and $\mathrm{C}=\mathrm{O}$ bonds, and hydrodeoxygenation to remove oxygen atoms. The aldol condensation of the furfural species with cyclic ketones was catalyzed by $\mathrm{NaOH}$ and the target condensation intermediates were obtained in yields of more than $90 \%$ at room temperature $\left(30^{\circ} \mathrm{C}\right.$ ) with a short reaction time (40 min). By using amorphous zirconium phosphate combined with $\mathrm{Pd} / \mathrm{C}$ as the catalyst, liquid cycloalkanes were produced at the optimal conditions with a yield of $76 \%$. When the combined solid catalyst was reused, the target products reduced after the second run but the initial yield could be largely recovered by recalcination of the spent zirconium phosphate. Considering that cyclopentanone and cyclohexanone can be easily produced from furfural (originating from hemicellulose) and phenol (originating from lignin), respectively, this condensation has the potential to achieve the integrated conversion of biomassderived cellulose, hemicellulose and lignin to jet fuel and/or diesel additives.

\section{Introduction}

Lignocellulosic biomass is a renewable resource with huge storage, wide distribution and fast carbon cycles during biomass growth and utilization. Biomass-derived fuels and chemicals are regarded as an alternative to fossil energy, and their development has obvious significance for environmental protection and reduced dependence on fossil energy. Therefore, converting lignocellulosic biomass into fuels has attracted worldwide attention during recent decades. ${ }^{1-4}$

Cellulose, hemicellulose and lignin are the three main components of a typical lignocellulosic biomass, however, the monosaccharide units (typically, glucose and xylose) and derivatives (5-hydroxymethylfurfural (HMF) and furfural (FF)) are limited to carbon chains of length 6 , while the phenolic units (typically, phenol-, guaiacol- and syringyl-based primary structures) are limited to carbon chains of length 9 . This results

${ }^{a}$ CAS Key Laboratory of Renewable Energy, Guangzhou Institute of Energy Conversion, Chinese Academy of Sciences, Guangzhou, 510650, P. R. China. E-mail: liuqy@ms.giec.ac.cn; zhangxh@ms.giec.ac.cn; Fax:+86-20-87057737; Tel: +86-20-87057751; +86-20-87057790

${ }^{b}$ University of Chinese Academy of Sciences, Beijing, 100049, P. R. China

$\uparrow$ Electronic supplementary information (ESI) available. See DOI: 10.1039/c8ra01723a in the fuels from direct hydrodeoxygenation of these platforms having short carbon chains., ${ }^{5,6}$ To synthesize long-chained alkanes with carbon numbers of more than 10, for jet fuel and diesel use, condensations between suitable biomassderived platforms with special groups are necessary to extend the carbon chains. ${ }^{6-9}$ Typically, the production of long-chained alkanes involves three steps: depolymerization of the lignocellulosic biomass into oxygenated platforms (FF, HMF, levulinic acid, $\gamma$-valerolactone and 2-methylfuran et al.); fuel precursor formation by condensation; and hydrodeoxygenation of the fuel precursors. ${ }^{\mathbf{9}, 10}$ Herein, the second step of platform condensation is the key to obtain structurally diversified fuel precursors; the desired platforms and condensation methods must be chosen in order to produce versatile hydrocarbon fuels by hydrodeoxygenation. ${ }^{11}$ Aldol condensations of FF/HMF and/or their derivatives with carbonyl groups like acetone, ${ }^{\mathbf{1 2 - 1 6}}$ hydroxyacetone, ${ }^{17}$ butaldehyde, ${ }^{18}$ 2-butanone, ${ }^{19}$ methyl isobutyl ketone, $^{20}$ levulinic acid ${ }^{11,21,22}$ and angelica lactone ${ }^{23}$ have commonly been conducted to obtain the $\mathrm{C}_{9}-\mathrm{C}_{16}$ fuel precursors, but these carbonyl compounds originate from fossil resources or are produced from biomass by multi-step reactions, leading to low efficiency and high cost for the entire synthesis. As an alternative, hydroxyalkylation-alkylation of FF and 2-methylfuran obtained by hydrodeoxygenation of $\mathrm{FF}$ was reported to produce $\mathrm{C}_{15}$ fuel precursors with a branched carbon 
framework..$^{24-27}$ Despite the fact that the precursor could be converted into branched long-chain hydrocarbons, the main drawback was that only hemicellulose (the least abundant component in a typical lignocellulosic biomass) could be utilized. Interestingly, alternative routes including direct $\mathrm{C}-\mathrm{C}$ bond formation by condensation of monosaccharides/furfurals, ${ }^{28} \alpha$-alkylation of ketones with 1-butanol, ${ }^{29}$ self-coupling by two HMF molecules ${ }^{30}$ and oligomerization of angelica lactone ${ }^{31,32}$ were used to produce $\mathrm{C}_{10}-\mathrm{C}_{15}$ precursors with high yields, and hydrodeoxygenation to the relative long-chained hydrocarbons was then conducted over supported metal catalysts. Instead of the common furfurals, these routes extended the platform molecules for target hydrocarbons by using diversified structures.

Compared to branched and normal hydrocarbons with long chains, cyclic counterparts show particular advantages in view of their low freezing points and high energy densities, which are preferential for drop-in jet and/or diesel fuels. ${ }^{33}$ Carbonylcontaining HMF and FF are the two main platforms which can be easily produced from biomass through a hydrolysisdehydration process. On the other hand, cyclopentanone (CP) and cyclohexanone $(\mathrm{CH})$ are two important cyclic ketones that have special carbons with $\alpha$-Hs. In particular, CP could be selectively produced by hydrogenation-rearrangement of hemicellulose-derived $\mathrm{FF}^{\mathbf{3 4 , 3 5}}$ and $\mathrm{CH}$ could be prepared with very high yield from lignin-derived phenol. ${ }^{36,37}$ Thus, production of cyclic hydrocarbons with long chains from these furfural species and cyclic ketones are attractive for the integrated utilization of biomass. ${ }^{38-40}$

Here, we developed a new route for the production of cycloalkanes with carbon chain lengths of 13-18 from FF/HMF and $\mathrm{CP} / \mathrm{CH}$ (Scheme 1). Aldol condensations of these furfural species with cyclic ketones $(\mathrm{CP}$ and $\mathrm{CH}$ ) were first conducted over a base catalyst to produce the oxygenated precursors with cyclic structures. Then these precursors were hydrogenated to thermally stable intermediates by saturating the $\mathrm{C}=\mathrm{C}$ and $\mathrm{C}=\mathrm{O}$ bonds over a metal catalyst. Finally they were transformed to the long-chained cycloalkanes by using a catalyst of metal combined with solid acid. The reaction parameters of each step were screened and the pathway for long-chained cycloalkane formation is discussed.

\section{Experimental section}

\subsection{Materials}

FF (99\%), HMF (98\%), CP (99\%), CH (99\%), $\mathrm{ZrOCl}_{2} \cdot 8 \mathrm{H}_{2} \mathrm{O}, \mathrm{Pt} / \mathrm{C}$ ( $5 \mathrm{wt} \%), \mathrm{Pd} / \mathrm{C}(5 \mathrm{wt} \%)$ and $\mathrm{Ru} / \mathrm{C}(5 \mathrm{wt} \%)$ were purchased from Shanghai Crystal Pure Reagent Co., Ltd., China. Analytical grade $\mathrm{NaOH}, \mathrm{KOH}, \mathrm{Ba}(\mathrm{OH})_{2}, \mathrm{LiOH}, \mathrm{K}_{2} \mathrm{CO}_{3}, \mathrm{Na}_{2} \mathrm{CO}_{3}, \mathrm{Mg}(\mathrm{OH})_{2}, \mathrm{H}_{3} \mathrm{PO}_{4}$ and $\mathrm{NH}_{4} \mathrm{H}_{2} \mathrm{PO}_{4}$ were purchased from Tianjin Fuchen Chemical Reagent Factory, China. $\mathrm{Nb}_{2} \mathrm{O}_{5} \cdot \mathrm{H}_{2} \mathrm{O}$ was purchased from the Conghua Tantalum Niobium Factory (Guangzhou, China). All these chemicals and reagents were used without further purification.

\subsection{Catalyst preparation}

Preparation of niobium phosphate (NbP). $6 \mathrm{~g} \mathrm{Nb}_{2} \mathrm{O}_{5} \cdot \mathrm{H}_{2} \mathrm{O}$ was added into $100 \mathrm{~mL} 5.0 \mathrm{~mol} \mathrm{~L}^{-1} \mathrm{H}_{3} \mathrm{PO}_{4}$ aqueous solution and vigorously stirred for $48 \mathrm{~h}$ at room temperature. Then the solid residue was collected by filtration and fully washed with deionized water until $\mathrm{pH}=5$. This was followed by drying at $120{ }^{\circ} \mathrm{C}$ and calcination at $400{ }^{\circ} \mathrm{C}$ for $3 \mathrm{~h}$ (heating ramp of $5{ }^{\circ} \mathrm{C} \min ^{-1}$ ) in static air before use.

Preparation of zirconium phosphate (ZrP). $10 \mathrm{~g} \mathrm{ZrOCl}_{2}$ - $8 \mathrm{H}_{2} \mathrm{O}$ and $7.14 \mathrm{~g} \mathrm{NH}_{4} \mathrm{H}_{2} \mathrm{PO}_{4}$ were each dissolved in $100 \mathrm{~mL}$ deionized $\mathrm{H}_{2} \mathrm{O}$ to obtain two transparent solutions. The two solutions were mixed at the calculated molar ratio of $\mathrm{P} / \mathrm{Zr}=2$ and reacted for $8 \mathrm{~h}$ at room temperature under agitation. The white precipitate was filtered, fully washed with deionized water, dried at $100{ }^{\circ} \mathrm{C}$ overnight, and calcined at a temperature of $400{ }^{\circ} \mathrm{C}$ for $4 \mathrm{~h}$ (heating ramp of $5^{\circ} \mathrm{C} \mathrm{min}^{-1}$ ) in static air before use.

\subsection{Catalyst characterization}

X-ray powder diffraction (XRD) patterns of catalysts were obtained using an X-ray diffractometer (X'Pert Pro MPD, Philip) with $\mathrm{Cu} \mathrm{K} \alpha$ radiation $(\lambda=0.154 \mathrm{~nm})$ operated at $40 \mathrm{kV}$ and $100 \mathrm{~mA}$.

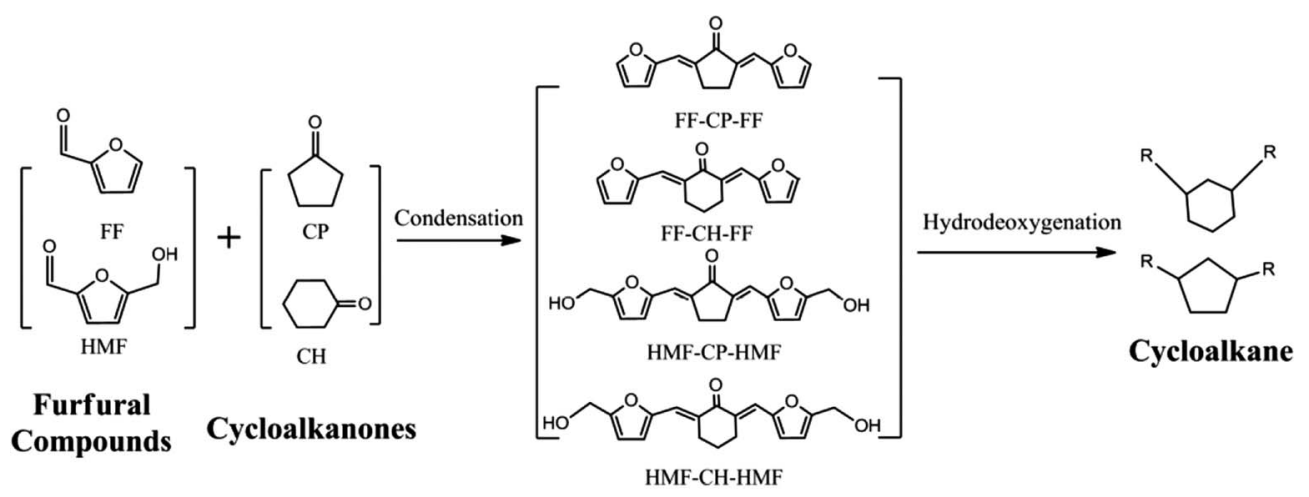

Condensation Intermediate

Scheme 1 Routes for long-chained cycloalkane production from furfural species and cyclic ketones. 
The Brunauer-Emmett-Teller (BET) specific surface areas were obtained from $\mathrm{N}_{2}$ isothermal adsorption-desorption measurements at $77 \mathrm{~K}$ using a QUADRASORB SI-MP-10/ PoreMaster analyzer equipped with QuadraWin software. The mesoporous volumes and pore size distributions were calculated by the desorption branch using the Barrett-JoynerHalenda (BJH) method.

Ammonia-temperature programmed desorption ( $\left.\mathrm{NH}_{3}-\mathrm{TPD}\right)$ was conducted in a U-tube quartz reactor (inner diameter 0.6 $\mathrm{cm}$ ) using an ASIQACIV200-2 automatic physical/chemical adsorption analyzer (Quantachrome, US). Catalyst ( $0.15 \mathrm{~g}$ ) was loaded into the U-tube quartz reactor and heated to $400{ }^{\circ} \mathrm{C}$ for $0.5 \mathrm{~h}$ (heating ramp of $10^{\circ} \mathrm{C} \mathrm{min}^{-1}$ ) under $30 \mathrm{~mL} \mathrm{~min}{ }^{-1}$ of $\mathrm{He}$ flow. The system was cooled to $50{ }^{\circ} \mathrm{C}, \mathrm{NH}_{3}$ was adsorbed onto the catalyst for $0.5 \mathrm{~h}$ until the saturation state was obtained and then the catalyst was flushed with a He flow of $30 \mathrm{~mL} \mathrm{~min}^{-1}$ to remove the physically adsorbed $\mathrm{NH}_{3}$. The adsorption and removal processes were monitored by the TCD signals. Then the system was heated to $825{ }^{\circ} \mathrm{C}$ with a heating ramp of $10{ }^{\circ} \mathrm{C} \mathrm{min}{ }^{-1}$ under the same He flow. The online MS (AMETEK DYCOR LCD200, US) was used to determine the effluent $\mathrm{NH}_{3}$ desorbed from the catalyst. The quantitative analysis of acidic sites was performed using a calibration loop of $250 \mu \mathrm{L}$ in which $5 \% \mathrm{NH}_{3}$ 95\% Ar mixed gas was used for the single point calibration.

Transmission electron microscopy (TEM) images were gained on a Gatan Ultra scan camera using a JEOL JEM-2100F instrument operated at $200 \mathrm{kV}$. The samples were ultrasonically dispersed in ethanol, and drops of each suspension were placed on carbon-coated copper grids and then dried in air.

Scanning electron microscopy (SEM) images were recorded using an S-4800 instrument operated at $2 \mathrm{kV}$. The samples were placed on a conductive carbon tape adhered to an aluminium sample holder.

Fourier transform infrared (FT-IR) spectra were recorded on a Bruker TENSOR27 spectrometer with a resolution of $4 \mathrm{~cm}^{-1}$. The samples were pelleted with $\mathrm{KBr}$ before measurement.

The Pd dispersion in $\mathrm{Pd} / \mathrm{C}$ was tested by $\mathrm{H}_{2}$-chemisorption using a Quantachrome-ASIQACIV200-2 automated gas sorption analyzer. The catalyst $(0.2 \mathrm{~g})$ was treated at $300{ }^{\circ} \mathrm{C}$ with a heating ramp of $5{ }^{\circ} \mathrm{C} \min ^{-1}$ under a hydrogen atmosphere $\left(30 \mathrm{~mL} \mathrm{~min}^{-1}\right)$. To clean the catalyst surface, the catalyst was further heated to $350{ }^{\circ} \mathrm{C}$ for $0.5 \mathrm{~h}$ under nitrogen $\left(30 \mathrm{~mL} \mathrm{~min}{ }^{-1}\right)$, and then cooled to $50{ }^{\circ} \mathrm{C}$ for the $\mathrm{H}_{2}$-chemisorption test.

\subsection{Aldol condensation of furfural species with cyclic ketones}

Aldol condensation of furfural species and cyclic ketones was conducted in a $250 \mathrm{~mL}$ conical flask under atmospheric pressure. Using FF and CP as example, $2 \mathrm{mmol} F F$ and $1 \mathrm{mmol} \mathrm{CP}$ were introduced into the flask, followed by the addition of $15 \mathrm{~mL} \mathrm{H}_{2} \mathrm{O}$ and a certain amount of basic catalyst. The condensation was conducted at $30{ }^{\circ} \mathrm{C}$ for $40-120 \mathrm{~min}$ in a water bath with vigorous stirring $(800 \mathrm{rpm})$. After the reaction, the solid product was filtrated, fully washed with a $5 \%$ aqueous ethanol solution and dried in a freeze dryer for $48 \mathrm{~h}$. A yellowish solid was finally obtained and was labeled as FF-CP-FF. The condensations of $\mathrm{FF}$ and $\mathrm{CH}, \mathrm{HMF}$ and $\mathrm{CP}$ and $\mathrm{HMF}$ and $\mathrm{CH}$ were carried out by the procedure mentioned above, and the solid intermediates were labeled as FF-CH-FF, HMF-CP-HMF and HMF-CH-HMF, respectively.

The structures of the aldol condensation intermediates were identified using ${ }^{13} \mathrm{C}$ NMR analysis (Bruker BioSpin $\mathrm{GmbH}$ ) using $\mathrm{CDCl}_{3}$ or DMSO as the solvent.

The yield of each condensation intermediate was calculated by the following equation:

$$
Y_{\mathrm{i}}=\frac{n_{\mathrm{i}} \times C_{\mathrm{i}}}{n_{\mathrm{f}} \times C_{\mathrm{f}}+n_{\mathrm{k}} \times C_{\mathrm{k}}} \times 100 \%
$$

where, $Y_{\mathrm{i}}$ is the yield of condensation intermediate collected; $n_{\mathrm{i}}$, $n_{\mathrm{f}}$ and $n_{\mathrm{k}}$ represent the moles of solid intermediate $\mathrm{i}$, furan and ketone introduced, respectively; and $C_{\mathrm{i}}, C_{\mathrm{f}}$ and $C_{\mathrm{k}}$ indicate the carbon numbers of solid intermediate $i$, introduced furan and ketone, respectively.

\subsection{Hydrodeoxygenation of condensation intermediates to cycloalkanes}

The hydrodeoxygenation of the condensation intermediates was carried out in a $50 \mathrm{~mL}$ stainless steel reactor with a mechanical stirrer. The condensation intermediate ( $1 \mathrm{mmol}$ ), $15 \mathrm{~mL} \mathrm{H}_{2} \mathrm{O}$ and a certain amount of catalyst (solid acid and metal) were added to the reactor. After purging five times with $\mathrm{H}_{2}$, the reaction system was pressured to $4 \mathrm{MPa}$ with $\mathrm{H}_{2}$ (room temperature). Then the reactor was heated to the target temperature and maintained at that temperature for the set time under vigorous stirring $(800 \mathrm{rpm})$. After the reaction, the reactor was cooled to room temperature, and $15 \mathrm{~mL}$ ethyl acetate was used to extract the organic products three times. The organic layer was analyzed by gas chromatography (GC, GC2014C, Shimadzu, Japan) and gas chromatography-mass spectrometry (GC-MS, Agilent 7890, US). For calculating the conversion percentage, the solid residue was collected by filtration, further rinsed with deionized water, collected by filtration again and dried in a freeze dryer for $48 \mathrm{~h}$.

For reuse, the combined catalyst ( $\mathrm{ZrP}$ and $\mathrm{Pd} / \mathrm{C}$ ) was recovered by centrifugation from the reaction mixture, thoroughly rinsed with deionized water and directly used for the next cycle. Considering that the components of the combined catalyst were hard to separate from each other, to ascertain which catalyst led to deactivation, comparative experiments were conducted by hydrothermal treatment of $\mathrm{ZrP}$ and $\mathrm{Pd} / \mathrm{C}$ at $300{ }^{\circ} \mathrm{C}$, followed by either recalcination at $400{ }^{\circ} \mathrm{C}$ in static air (for $\mathrm{ZrP}$ ) or $300{ }^{\circ} \mathrm{C}$ in $30 \mathrm{~mL} \min ^{-1}$ of $\mathrm{H}_{2}$ flow (for $\mathrm{Pd} / \mathrm{C}$ ); heating ramps of $10{ }^{\circ} \mathrm{C} \min ^{-1}$ were used for both. For monitoring the saturation of $\mathrm{C}=\mathrm{C}$ and $\mathrm{C}=\mathrm{O}$ bonds by hydrogenation in the solid intermediates, the sole $\mathrm{Pd} / \mathrm{C}$ catalyst was used at relatively low temperatures according to the hydrodeoxygenation process. The structures of these hydrogenation intermediates were identified using ${ }^{13} \mathrm{C}$ NMR analysis (Bruker Biospin $\mathrm{GmbH}$ ) using $\mathrm{CDCl}_{3}$ or DMSO as the solvent.

The quantitative analysis of the extracted liquid products was determined by GC (SHIMADZU 2014C) with a flame ionization detector (FID) and a HP-INNOWAX column $(30 \mathrm{~m} \times$ 

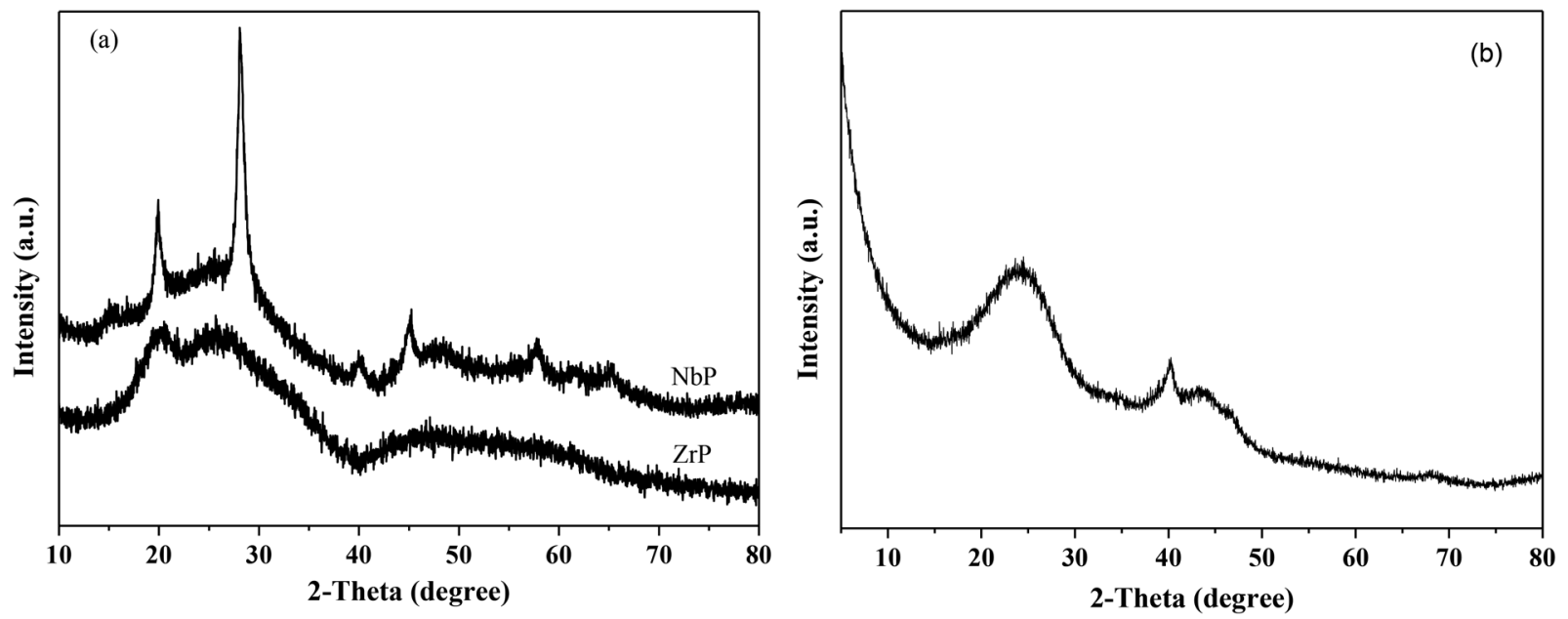

Fig. 1 XRD patterns of fresh $\mathrm{ZrP}$ and $\mathrm{NbP}(\mathrm{a})$, and fresh $\mathrm{Pd} / \mathrm{C}(\mathrm{b})$.

$0.25 \mathrm{~mm} \times 0.25 \mu \mathrm{m})$. The oven temperature was programmed initially at $60{ }^{\circ} \mathrm{C}$ for $2 \mathrm{~min}$, and then ramped up to $260{ }^{\circ} \mathrm{C}$ at a heating rate of $10{ }^{\circ} \mathrm{C} \mathrm{min}^{-1}$ and held at this temperature for another $10 \mathrm{~min}$. The injector was kept at $280{ }^{\circ} \mathrm{C}$ and used in splitting mode $(5: 1)$ with helium as the carrier gas. Tridecane was used as the internal standard. The qualitative analysis of liquid products was carried out by GC-MS (Agilent 7890, US) used with the same capillary column and analytical conditions to those of the GC analysis. The gas products $\left(\mathrm{CH}_{4}, \mathrm{C}_{2} \mathrm{H}_{6}\right.$ and $\mathrm{C}_{3} \mathrm{H}_{8}$, etc.) were collected with a sampling bag and analyzed by a GC 9800 chromatography tester equipped with a FID and a packed column (Porapak-Q column, $3 \mathrm{~m} \times 3 \mathrm{~mm}$ ). The quantification of gas products was conducted using a typical external standard.

The conversion of intermediates and yield of liquid product was calculated by the following equations:

$$
\begin{aligned}
& \text { Conversion }(\%)=m_{\text {intermediate residue }} / \\
& m_{\text {intermediate loaded }} \times 100 \% \\
& m_{\text {intermediate residue }}=m_{\text {solid residue }}-m_{\text {catalyst }} \\
& Y_{\mathrm{pi}}=\frac{n_{\mathrm{pi}} \times C_{\mathrm{pi}}}{n_{\mathrm{i}} \times C_{\mathrm{i}}} \times 100 \%
\end{aligned}
$$

where, $m_{\text {intermediate }}$ residue and $m_{\text {intermediate loaded }}$ mean the intermediate left after the reaction and the intermediate loaded
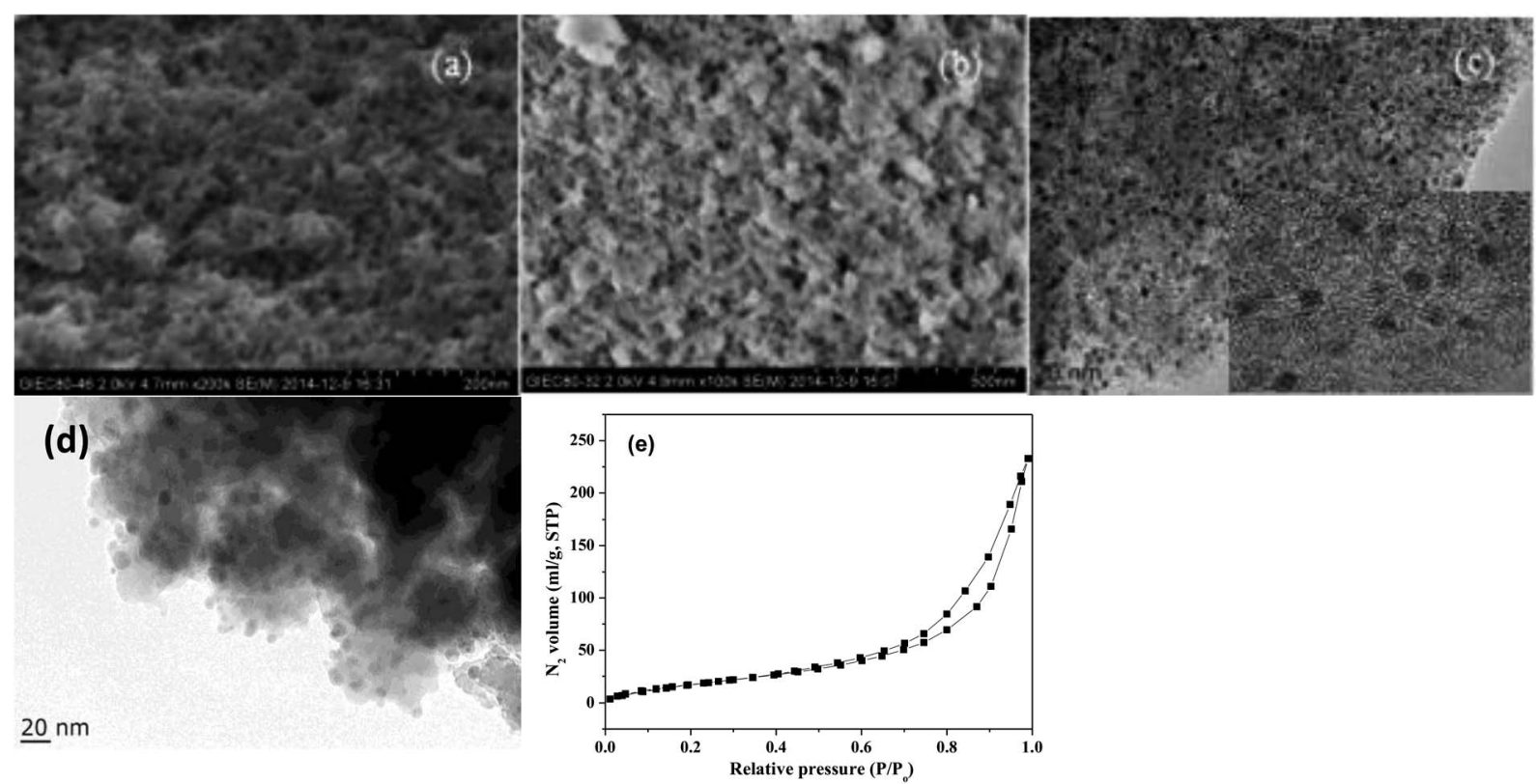

Fig. 2 SEM images of fresh $\mathrm{NbP}(\mathrm{a})$ and $\mathrm{ZrP}(\mathrm{b})$. TEM images of $\mathrm{Pd} / \mathrm{C}$ (c) and $\mathrm{ZrP}(\mathrm{d}) . \mathrm{N}_{2}$ adsorption-desorption curve of ZrP (e). The inset in (c) shows the HRTEM image of $P d / C$. 
Table 1 Textural properties, acidic densities and metal dispersion of solid acids and $\mathrm{Pd} / \mathrm{C}$

\begin{tabular}{llcccc}
\hline Entry & Catalyst & Surface $\operatorname{area}^{a}\left(\mathrm{~m}^{2} \mathrm{~g}^{-1}\right)$ & Pore volume $^{b}\left(\mathrm{~cm}^{3} \mathrm{~g}^{-1}\right)$ & $\begin{array}{l}\text { Average pore } \\
\text { diameter }^{b}(\mathrm{~nm})\end{array}$ & $\begin{array}{l}\text { Acidic density } \\
\left(\mathrm{mmol} \mathrm{g}^{-1}\right)\end{array}$ \\
\hline 1 & ZrP & 112.7 & 0.25 & 6.8 & 1.55 \\
2 & Spent ZrP & 93.9 & 0.27 & 5.6 & - \\
3 & NbP & 78.1 & 0.20 & 7.9 & - \\
4 & Pd/C & 1025.9 & 0.28 & 3.8 & - \\
5 & Spent Pd/C & 932.5 & 0.25 & 4.3 & - \\
\hline
\end{tabular}

${ }^{a}$ The surface areas were estimated by the BET method using $\mathrm{N}_{2}$ at $-196{ }^{\circ} \mathrm{C} .{ }^{b}$ The pore volume and average pore diameter were determined by using the desorption branch and BJH method. ${ }^{c}$ The acidic densities were calculated by $\mathrm{NH}_{3}$-TPD measurements and a calibration loop of $250 \mu \mathrm{L} .{ }^{d}$ The dispersion of $\mathrm{Pd}$ was determined by $\mathrm{H}_{2}$-chemisorption. ${ }^{e}$ The spent $\mathrm{ZrP}$ was treated at $300{ }^{\circ} \mathrm{C}$ for $3 \mathrm{~h}$, dried and recalcinated at $400{ }^{\circ} \mathrm{C}$ for $4 \mathrm{~h}$. The spent $\mathrm{Pd} / \mathrm{C}$ was treated at $300{ }^{\circ} \mathrm{C}$ for $3 \mathrm{~h}$, dried and recalcinated at $300{ }^{\circ} \mathrm{C}$ for $3 \mathrm{~h}$ under $\mathrm{H}_{2}$ flow.

into the reactor by weight, respectively; $m_{\text {solid residue }}$ and $m_{\text {catalyst }}$ represent the weight of solid collected after the reaction and the weight of catalyst introduced, respectively; $Y_{\mathrm{pi}}$ is the yield of product $\mathrm{i}$ by hydrodeoxygenation; $n_{\mathrm{pi}}$ and $C_{\mathrm{pi}}$ represent the moles of products $i$ and carbon numbers of product $i$, respectively; and $n_{\mathrm{i}}$ and $C_{\mathrm{i}}$ indicate the moles of condensation intermediate loaded and carbon number of condensation intermediate, respectively.

The turnover frequency (TOF) of the Pd/C based catalysts was determined by using the following equation:

TOF $\left(\mathrm{s}^{-1}\right)=$ converted FF-CP-FF in $\mathrm{mmol} /$

$$
((\text { exposed } \mathrm{Pd} \text { atom }) \times(\text { acid in } \mathrm{mmol}) \times \text { second })
$$

\section{Results and discussion}

\subsection{Catalyst characterization}

Fig. 1 shows the XRD patterns of freshly prepared NbP, ZrP and $\mathrm{Pd} / \mathrm{C}$ catalysts. The obvious diffractions at $2 \theta=19.8^{\circ}, 28.0^{\circ}$, $40.2^{\circ}, 44.9^{\circ}, 57.8^{\circ}$ and $65.1^{\circ}$ indicate the crystalline nature of $\mathrm{NbP}$, consistent with the previous report. ${ }^{41}$ On the other hand, the very weak and broadened diffractions observed in the range of $15-70^{\circ}$ for $\mathrm{ZrP}$, show that $\mathrm{ZrP}$ presents an amorphous nature. For $\mathrm{Pd} / \mathrm{C}$, peaks at $2 \theta=40.1^{\circ}, 43.9^{\circ}$ and $68.3^{\circ}$ were obtained but the intensities were weak, implying that the Pd particles are tiny and highly dispersed on the activated carbon surface.

The SEM images of NbP and ZrP, the TEM images of $\mathrm{Pd} / \mathrm{C}$ and $\mathrm{ZrP}$, and the $\mathrm{N}_{2}$ adsorption-desorption curve of $\mathrm{ZrP}$ are shown in Fig. 2. Based on the SEM analysis, the particle size of the $\mathrm{NbP}$ was in the range of $10-20 \mathrm{~nm}$, and that of $\mathrm{ZrP}$ was about $20 \mathrm{~nm}$. The particle size of $\mathrm{ZrP}$ was consistent with the results obtained from TEM measurement. For Pd/C, the Pd particles were observed and their size was in the range of 2-3 nm, which is consistent with the result of XRD. As shown in Fig. 2e and Table 1, the surface area, pore capacity and diameter of ZrP were $112 \mathrm{~m}^{2} \mathrm{~g}^{-1}, 0.25 \mathrm{~mL}$ and $6.8 \mathrm{~nm}$, respectively, which are larger than those of NbP aside from the pore diameter. Both NbP and ZrP showed similar acidity, and both weak acidic sites (observed from $\mathrm{NH}_{3}$ desorption at temperatures below $350{ }^{\circ} \mathrm{C}$ ) and strong acidic sites (observed from $\mathrm{NH}_{3}$ desorption at temperatures higher than $450{ }^{\circ} \mathrm{C}$ ) were simultaneously presented on the two catalysts' surfaces (Fig. 3). As compared with NbP $\left(0.58 \mathrm{mmol} \mathrm{g}^{-1}\right)$, ZrP presented a much higher acid density of $1.55 \mathrm{mmol} \mathrm{g}^{-1}$ (Table 1). The $\mathrm{Pd} / \mathrm{C}$ showed a large surface area of more than $1000 \mathrm{~m}^{2} \mathrm{~g}^{-1}$ with significant numbers of mesopores. Meanwhile, the Pd dispersion was as high as 0.49 according to the $\mathrm{H}_{2}$-chemisorption analysis. After hydrothermal treatment and recalcination, the surface area and acidic sites of the used $\mathrm{ZrP}$ were reduced, but more than $80 \%$ of the original values were still retained while the pore volume and diameter changed a little. The surface area of the used Pd/C was $90 \%$ of that of the fresh catalyst. The Pd dispersion decreased to 0.36 , although high dispersion still remained during the hydrothermal treatment.

Fig. 4 presents the FT-IR spectra of fresh, hydrothermally treated, and regenerated ZrP. The three samples presented the stretching vibrations of $\mathrm{P}-\mathrm{OH}$ (the Bronsted acidic centers, $\left.2354 \mathrm{~cm}^{-1}\right)$, and tetrahedral $\mathrm{P}-\mathrm{O}\left(1082 \mathrm{~cm}^{-1}\right)$, and the bending vibration of $\mathrm{P}-\mathrm{O}-\mathrm{P}\left(752 \mathrm{~cm}^{-1}\right)$, similar to the previous reports. ${ }^{42-45}$ After hydrothermal treatment, the peak intensity corresponding to $\mathrm{P}-\mathrm{O}-\mathrm{P}$ significantly reduced while that corresponding to $\mathrm{P}-\mathrm{OH}$ increased, indicating that $\mathrm{ZrP}$ hydrolysis occurred during the treatment process. After recalcination, the $\mathrm{P}-\mathrm{O}-\mathrm{P}$ was regenerated at the expense of $\mathrm{P}-\mathrm{OH}$, based on the corresponding intensity changes. This means that the hydrolyzed $\mathrm{P}-\mathrm{OH}$ could be re-condensed to recover the original

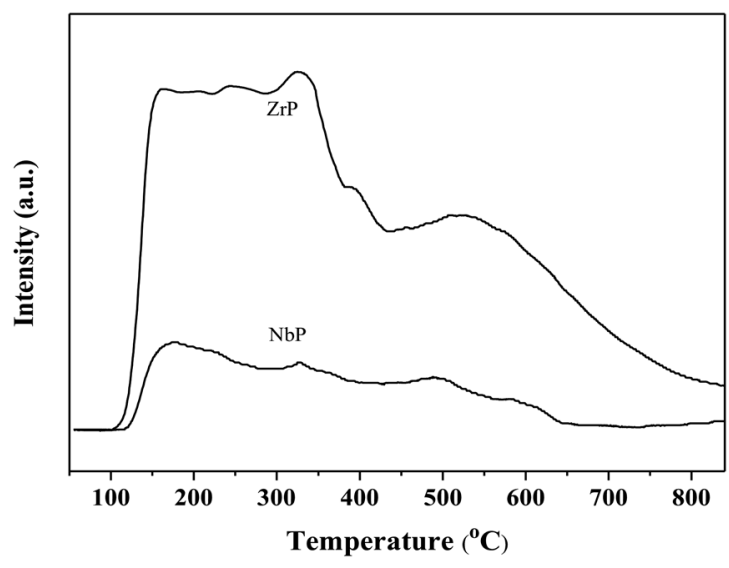

Fig. $3 \mathrm{NH}_{3}$-TPD profiles of fresh $\mathrm{ZrP}$ and $\mathrm{NbP}$. 


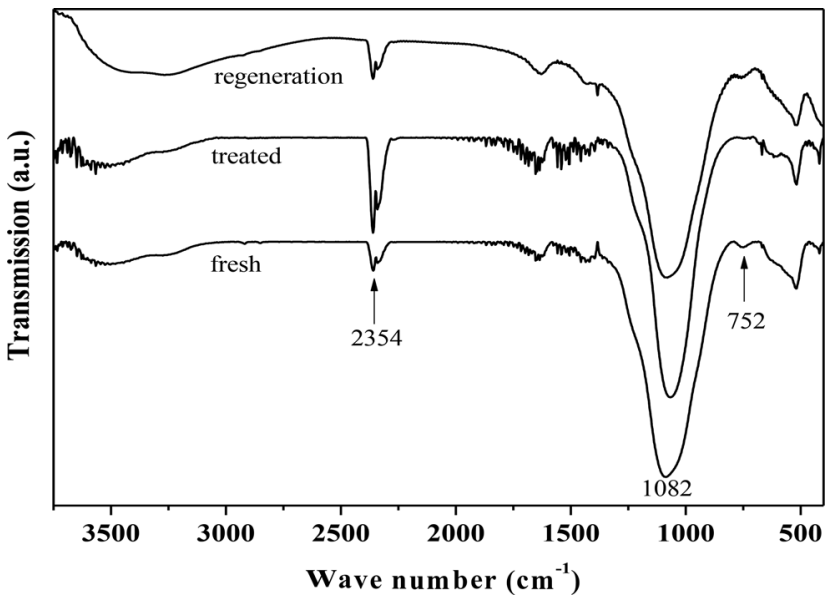

Fig. 4 FT-IR spectra of fresh, hydrothermally treated, and regenerated ZrP.

structure. It was noted that the peak associated with the $\mathrm{Zr}-\mathrm{O}-\mathrm{P}$ framework was largely unchanged for the three samples, showing the hydrothermal stability of the prepared ZrP.

\subsection{Condensation of furfural species with cyclic ketones}

Aldol condensations of biomass-derived aldehydes (FF and $\mathrm{HMF}$ ) with cyclic ketones ( $\mathrm{CP}$ and $\mathrm{CH}$ ) with mole ratios of $2: 1$ were used to synthesize $\mathrm{C}_{10}-\mathrm{C}_{18}$ precursors for downstream long-chained cycloalkane production. The condensation mechanism using FF and $\mathrm{CP}$ as an example is shown in Scheme S1. $\dagger$ The production of FF-CP-FF originates from consecutive $\mathrm{C}-\mathrm{C}$ bond formation via a classical carbanion mechanism followed by dehydration over a base catalyst.

We began our study by choosing the aldol condensation of $\mathrm{FF}$ and $\mathrm{CP}$ as the model reaction to investigate. Various alkali catalysts ( $\mathrm{LiOH}, \mathrm{NaOH}, \mathrm{KOH}, \mathrm{Ba}(\mathrm{OH})_{2}, \mathrm{Mg}(\mathrm{OH})_{2}, \mathrm{Na}_{2} \mathrm{CO}_{3}$, $\mathrm{Na}_{2} \mathrm{CO}_{3}$ ) were used to catalyze this reaction at $30{ }^{\circ} \mathrm{C}$ (Table 2). The aldol condensation of FF with CP could not take place without any catalyst. However, when only a $5 \%$ molar equivalent of $\mathrm{NaOH}$ (relative to $\mathrm{CP}$ ) was added into the mixture of $\mathrm{FF}$ and $\mathrm{CP}$ (at a FF : CP mole ratio of $2: 1$ ), the reaction took place quickly, producing a $68 \%$ yield of solid product in $40 \mathrm{~min}$. After increasing the $\mathrm{NaOH}$ dosage to $10 \%$, the conversion of $\mathrm{FF}$ and CP reached $100 \%$ (based on GC measurements; data not shown), and was accompanied by a high FF-CP-FF yield of $94 \%$. Further increasing the $\mathrm{NaOH}$ to $20 \%$ slightly increased the yield of isolated condensation product FF-CP-FF to $96 \%$. Other strong bases such as $\mathrm{LiOH}, \mathrm{KOH}$ and $\mathrm{Ba}(\mathrm{OH})_{2}$ also showed excellent performance resulting in target product yields of $90 \%$ and above. However, no condensation product was observed when using the weak alkalis $\mathrm{Mg}(\mathrm{OH})_{2}, \mathrm{Na}_{2} \mathrm{CO}_{3}$ and $\mathrm{K}_{2} \mathrm{CO}_{3}$ as the catalysts even after $2 \mathrm{~h}$, showing that such condensation preferentially takes place over a strong base. Because the strong base $\mathrm{NaOH}$ showed an excellent performance in the aldol condensation of FF with $\mathrm{CP}$, we further employed $\mathrm{NaOH}$ for aldol condensations of $\mathrm{FF}$ with $\mathrm{CH}$, and $\mathrm{HMF}$ with $\mathrm{CP} / \mathrm{CH}$. No obvious difference was observed when $\mathrm{CH}$ was used to replace $\mathrm{CP}$ as the starting material, which is in accordance with results from a previous study. ${ }^{46}$ Condensation products (FF-CP-FF and FF-CH-FF) were obtained in yields of over 90\% from the condensation of FF with both $\mathrm{CH}$ and $\mathrm{CP}$. When HMF was used as the starting material instead of $\mathrm{FF}$, isolated condensation products (HMF-CP-HMF and HMF-CH-HMF) were obtained in over $95 \%$ yield. The condensation intermediates were yellowish for FF-CP-FF, FF-CH-FF and HMF-CH-HMF, and red for HMF$\mathrm{CP}-\mathrm{HMF}$, as seen in the photographs of the isolated solid intermediates (Fig. S1 $\dagger$ ). The molecular structures of these intermediates were determined by ${ }^{13} \mathrm{C}$ NMR measurement, which confirmed the synthesis of the desired products by aldol condensation without any impurities (Fig. S2-S4 and S6(a)†).

\subsection{Long-chain cycloalkanes by hydrodeoxygenation of condensation intermediates}

After obtaining the intermediates from the condensation of furfural species with cyclic ketones, we explored the

Table 2 Condensation of furfural species and cycle ketones over base catalysts ${ }^{a}$

\begin{tabular}{|c|c|c|c|c|c|c|}
\hline Entry & Furfural species & Cyclic ketones & Catalyst dosage $^{b}(\mathrm{~mol} \%)$ & Time (min) & Product & Isolated yield ${ }^{c}(\mathrm{C}-\mathrm{mol} \%)$ \\
\hline 1 & $\mathrm{FF}$ & $\mathrm{CP}$ & - & 40 & FF-CP-FF & 0 \\
\hline 2 & $\mathrm{FF}$ & $\mathrm{CP}$ & $\mathrm{NaOH}, 5$ & 40 & FF-CP-FF & 68 \\
\hline 4 & $\mathrm{FF}$ & $\mathrm{CP}$ & $\mathrm{NaOH}, 20$ & 40 & FF-CP-FF & 96 \\
\hline 5 & $\mathrm{FF}$ & $\mathrm{CP}$ & $\mathrm{KOH}, 10$ & 40 & FF-CP-FF & 93 \\
\hline 6 & $\mathrm{FF}$ & $\mathrm{CP}$ & LiOH, 10 & 40 & FF-CP-FF & 87 \\
\hline 9 & $\mathrm{FF}$ & $\mathrm{CP}$ & $\mathrm{Na}_{2} \mathrm{CO}_{3}, 10$ & 120 & FF-CP-FF & 0 \\
\hline 10 & $\mathrm{FF}$ & $\mathrm{CP}$ & $\mathrm{K}_{2} \mathrm{CO}_{3}, 10$ & 120 & FF-CP-FF & 0 \\
\hline 11 & $\mathrm{FF}$ & $\mathrm{CH}$ & $\mathrm{NaOH}, 10$ & 40 & FF-CH-FF & 92 \\
\hline 12 & HMF & $\mathrm{CP}$ & $\mathrm{NaOH}, 10$ & 40 & HMF-CP-HMF & 96 \\
\hline 13 & HMF & $\mathrm{CH}$ & $\mathrm{NaOH}, 10$ & 40 & HMF-CH-HMF & 98 \\
\hline
\end{tabular}

${ }^{a}$ All the reactions were conducted at $30{ }^{\circ} \mathrm{C}$ and the mole ratio of furfural compounds to cyclic ketone was $2: 1 .^{b}$ Relative to cyclic ketone. ${ }^{c}$ The isolated yield was calculated for the target product based on the cyclic ketone. 
hydrodeoxygenation of the condensation intermediates to cycloalkanes in an autoclave equipped with a mechanical stirrer.

Solvent is necessary for the hydrodeoxygenation process because the condensation products are all solid. The common oxy-organic solvents (methanol, ethanol and tetrahydrofuran) are not suitable because they could be digested under the hydrodeoxygenation conditions. Water is comparatively stable during intermediate hydrodeoxygenation, and is suitable as a green and economical solvent. Supported metal combined with solid acid is typically used as an effective catalyst for this process. For example, Huang et al. reported that carbonsupported noble metals $(\mathrm{Pd} / \mathrm{C}$ and $\mathrm{Pt} / \mathrm{C})$ combined with solid acids $\left(\mathrm{NbOPO}_{4}\right.$ and $\left.\mathrm{TaOPO}_{4}\right)$ are efficient in dehydration/ hydrogenation of fuel precursors into liquid alkanes with water as the reaction medium. ${ }^{47}$

Using water as the solvent, we employed a one-pot hydrodeoxygenation of the FF-CP-FF intermediate into long-chained cycloalkanes. A low intermediate conversion of less than $10 \%$ as well as negligible cycloalkane production (with a summed yield below 5\%) were obtained when using $\mathrm{Pd} / \mathrm{C}, \mathrm{Pt} / \mathrm{C}$ or $\mathrm{Ru} / \mathrm{C}$ alone as catalysts (Fig. 5a), suggesting that oxygen removal is a main barrier for alkane formation in the current reaction conditions. The addition of solid acid significantly increased the conversion and the cycloalkane yield. We calculated the average TOF of $\mathrm{Pd} / \mathrm{C}$ combined with $\mathrm{ZrP}$ and $\mathrm{NbP}$ catalysts from the Pd dispersion, respective acidic sites and FF-CP-FF conversion at $3 \mathrm{~h}$. The values of $0.47 \mathrm{~s}^{-1}$ and $0.87 \mathrm{~s}^{-1}$ were obtained for $\mathrm{Pd} / \mathrm{C}$ plus ZrP, and Pd/C plus NbP, respectively; NbP has a much lower value for acidic density. Fixing $\mathrm{Pd} / \mathrm{C}$ as the hydrogenation catalyst, $38.7 \%$ and $70.0 \%$ of cycloalkanes were obtained with the addition of $\mathrm{NbP}$ and $\mathrm{ZrP}$, respectively, evidencing their obvious promotion effect in this process. The yield of cycloalkanes obtained with ZrP was much higher than that with NbP, because the superior acidic properties of $\mathrm{ZrP}$ could enhance dehydration and produce more cycloalkanes. As shown in Fig. S7, $\dagger$ the cycloalkanes with 13-15 carbon atoms were the main products apart from some minor oxygenated compounds at retention times of more than 15 min. Because the carbon chain of the FF-CP-FF intermediate contains 15 carbon atoms, the formation of $\mathrm{C}_{13}$ and $\mathrm{C}_{14}$ was ascribed to hydrocracking during the hydrodeoxygenation process. Among these products, the $\mathrm{C}_{13}$ and $\mathrm{C}_{14}$ cycloalkanes presented as the major products. $54 \%$ of $\mathrm{C}_{13}-\mathrm{C}_{15}$ cycloalkanes were produced when using $\mathrm{Pt} / \mathrm{C}$ combined with $\mathrm{ZrP}$ as the catalyst. This indicates that $\mathrm{Pd} / \mathrm{C}$ and $\mathrm{ZrP}$ are preferable for this hydrodeoxygenation. Additionally, gas products including $\mathrm{C}_{1}-\mathrm{C}_{5}$ light alkanes were observed;
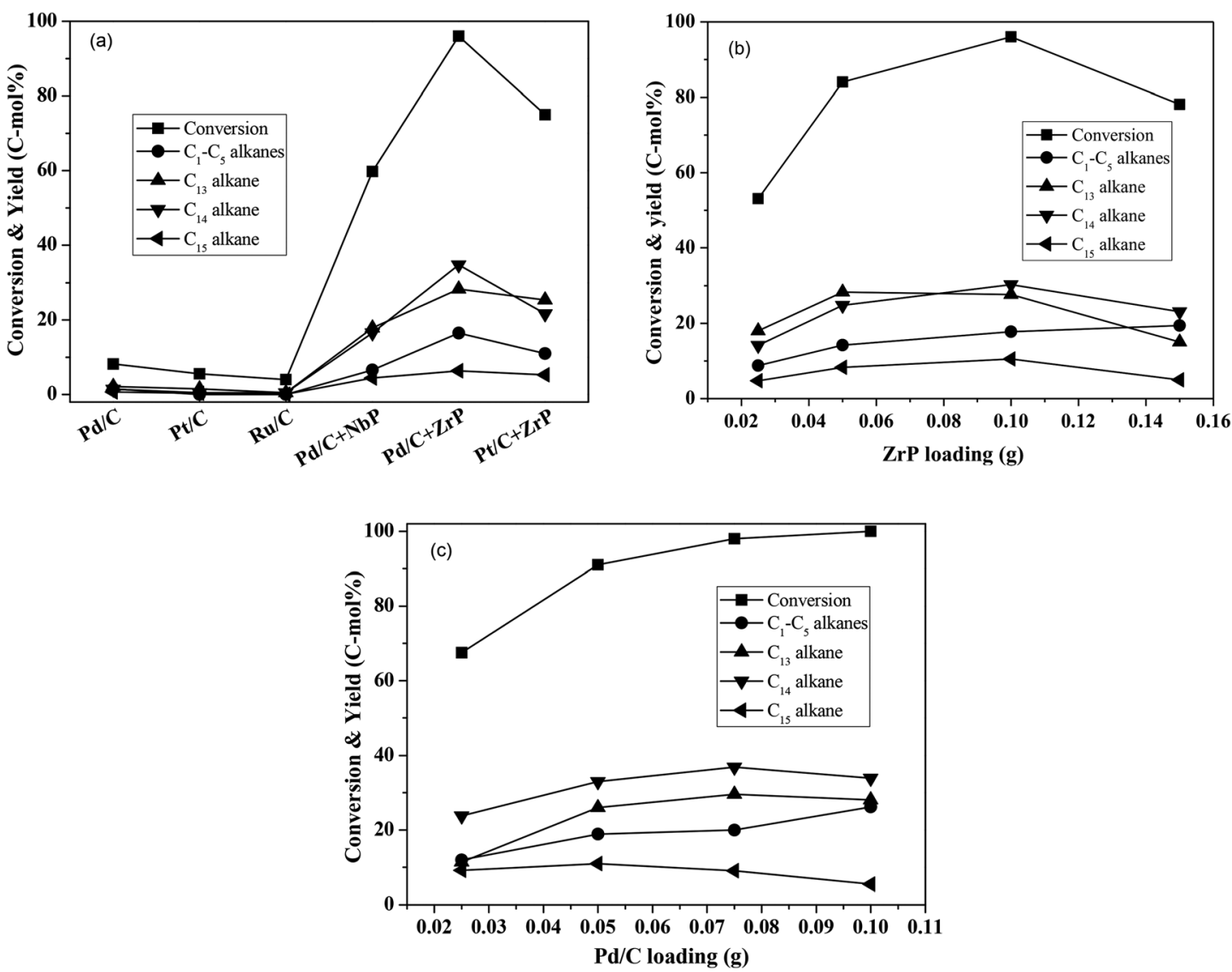

Fig. 5 Hydrodeoxygenation of the FF-CP-FF intermediate to hydrocarbons over different solid acids and metals supported on activated carbon catalysts (a), with different ZrP loadings (b), and with different $\mathrm{Pd} / \mathrm{C}$ loadings (c). Reaction conditions: $1.0 \mathrm{mmol} \mathrm{FF-CP-FF}, 15 \mathrm{~mL} \mathrm{H} \mathrm{O}_{2} \mathrm{O}, 0.05 \mathrm{~g}$ metal supported on carbon, $0.10 \mathrm{~g}$ solid acid, $4 \mathrm{MPa} \mathrm{H}_{2}$ pressure, $300{ }^{\circ} \mathrm{C}, 3 \mathrm{~h}$. 

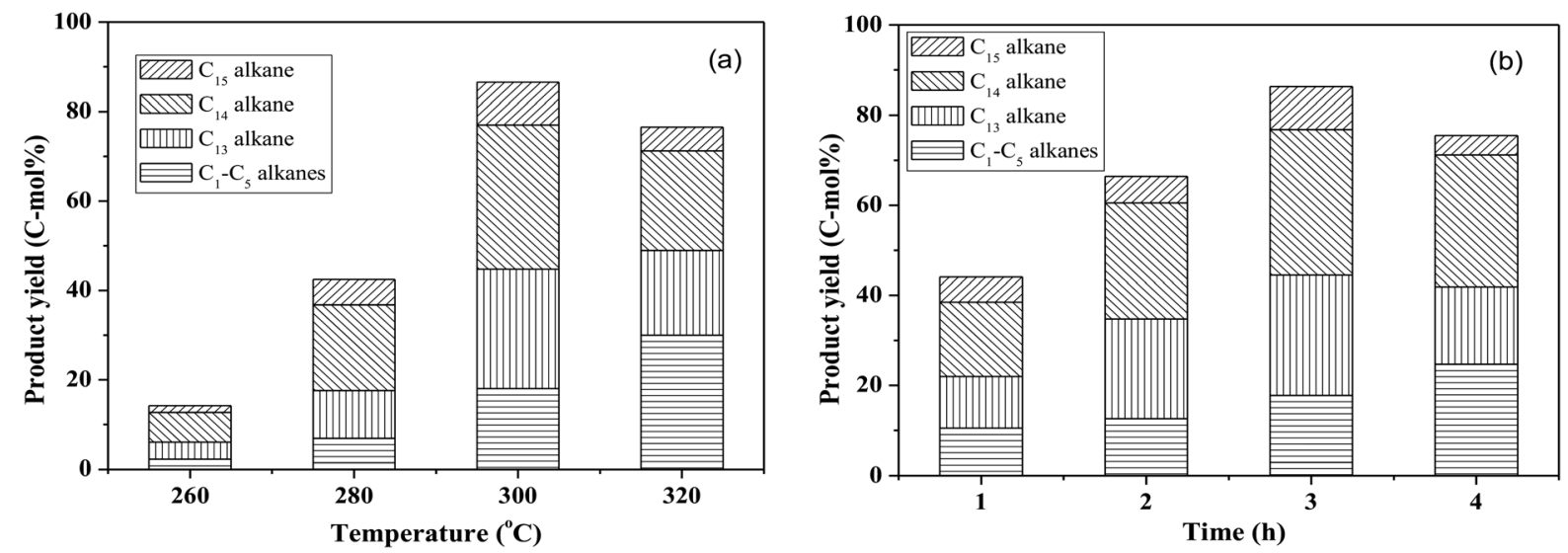

Fig. 6 The influence of reaction temperature (a) and time (b) on the hydrodeoxygenation of the FF-CP-FF intermediate over ZrP and Pd/C. Reaction conditions: $1.0 \mathrm{mmol} F \mathrm{~F}-\mathrm{CP}-\mathrm{FF}, 15 \mathrm{~mL} \mathrm{H} \mathrm{H}_{2} \mathrm{O} 0.05 \mathrm{~g} \mathrm{Pd} / \mathrm{C}, 0.10 \mathrm{~g} \mathrm{ZrP}, 4 \mathrm{MPa} \mathrm{H}_{2}$ pressure.

the existence of solid acid promotes the formation of such products.

$\mathrm{ZrP}$ and $\mathrm{Pd} / \mathrm{C}$ loadings were further investigated and the results are shown in Fig. 5b-c. With increasing $\mathrm{ZrP}$ from $0.025 \mathrm{~g}$ to $0.1 \mathrm{~g}$ (fixing the $\mathrm{Pd} / \mathrm{C}$ dosage at $0.05 \mathrm{~g}$ ), the intermediate conversion and cycloalkane yield significantly increased from $53 \%$ to $96 \%$ and $47-76 \%$, respectively, suggesting that the acid catalyst ZrP plays the critical role in oxygen removal. However, further increasing $\mathrm{ZrP}$ to $0.15 \mathrm{~g}$ led to a significant decrease in the cycloalkane yield, to $43 \%$, as well as reduced conversion, which is perhaps caused by the intermediate coking and/or the produced cycloalkane hydrocracking to short-chain alkanes. In addition to the target products, the light alkanes (mostly $\mathrm{CH}_{4}$, $\mathrm{C}_{2} \mathrm{H}_{6}, \quad \mathrm{C}_{3} \mathrm{H}_{8}$ and trace butane, pentane) increased with increasing $\mathrm{ZrP}$ and reached the highest proportion of $19 \%$ at $0.15 \mathrm{~g}$ ZrP. When the ZrP amount was fixed at $0.1 \mathrm{~g}$, the cycloalkane yield increased with increasing amounts of $\mathrm{Pd} / \mathrm{C}$ and the highest yield of $74 \%$ was obtained at $0.075 \mathrm{~g} \mathrm{Pd} / \mathrm{C}$. When $\mathrm{Pd} / \mathrm{C}$ was further increased to $0.1 \mathrm{~g}$, the target products decreased but to a lesser degree than occurred with excess ZrP. This result shows that hydrocracking more likely occurred over solid acid. Based on the conversion efficiency and detected products by GC analysis, more than $90 \%$ of the carbon balance was obtained under the optimized conditions, showing that coking was suppressed during the process. At the same time, a decreased carbon balance of about $80 \%$ was observed in the case of excess $\mathrm{ZrP}$ or at a lower ratio of $\mathrm{Pd} / \mathrm{C}$ to $\mathrm{ZrP}$ indicating that coking takes places with excessive solid acid. It is noted that the highest yield of $76 \%$ of cycloalkanes is comparable to that obtained in previous reports. ${ }^{18-20}$

By using the combined catalyst (0.05 $\mathrm{g} \mathrm{Pd} / \mathrm{C}$ and $0.1 \mathrm{~g} \mathrm{ZrP})$, we studied the influences of reaction temperature and time on cycloalkane production from the FF-CP-FF intermediate (Fig. 6). At a low temperature of $260{ }^{\circ} \mathrm{C}$, a total cycloalkane yield of only $13 \%$ was obtained, but this greatly increased to $36 \%$ and $70 \%$ when increasing the temperature to $280{ }^{\circ} \mathrm{C}$ and $300{ }^{\circ} \mathrm{C}$, respectively. However, further increasing the reaction temperature to $320{ }^{\circ} \mathrm{C}$, decreased the cycloalkane yield to $49 \%$. Additionally, the proportion of light alkanes increased with increasing temperature, reaching the highest value of $29 \%$ at $320{ }^{\circ} \mathrm{C}$ due to the enhanced hydrocracking at higher temperatures. Among these light alkanes, $\mathrm{CH}_{4}$ was selectively produced ( $>85 \%$ of the gaseous products) no matter what temperature was used (Fig. 7). The impact of reaction time was also investigated at $300{ }^{\circ} \mathrm{C}$. At the short time of $1 \mathrm{~h}$, the yield of $\mathrm{C}_{13}-\mathrm{C}_{15}$ cycloalkanes was $34 \%$. The cycloalkane yield increased to $56 \%$ and $70 \%$ when prolonging the reaction time to $2 \mathrm{~h}$ and $3 \mathrm{~h}$, respectively. However, further increasing the time led to a decreased cycloalkane yield. Similar to the effect of temperature, the lengthened time induced hydrocracking during the hydrodeoxygenation process and produced more light alkanes, resulting in reduced target products.

Hydrodeoxygenation of FF-CP-FF to produce cycloalkanes involves saturation of $\mathrm{C}=\mathrm{O} / \mathrm{C}=\mathrm{C}$ bonds followed by oxygen removal. To ascertain this process, FF-CP-FF was hydrogenated into water-soluble oxygenated chemicals at the low temperature of $150{ }^{\circ} \mathrm{C}$ when using the single $\mathrm{Pd} / \mathrm{C}$ catalyst (Fig. S5 $\dagger$ ) and the structures of the products were analyzed by the ${ }^{13} \mathrm{C} N M R$

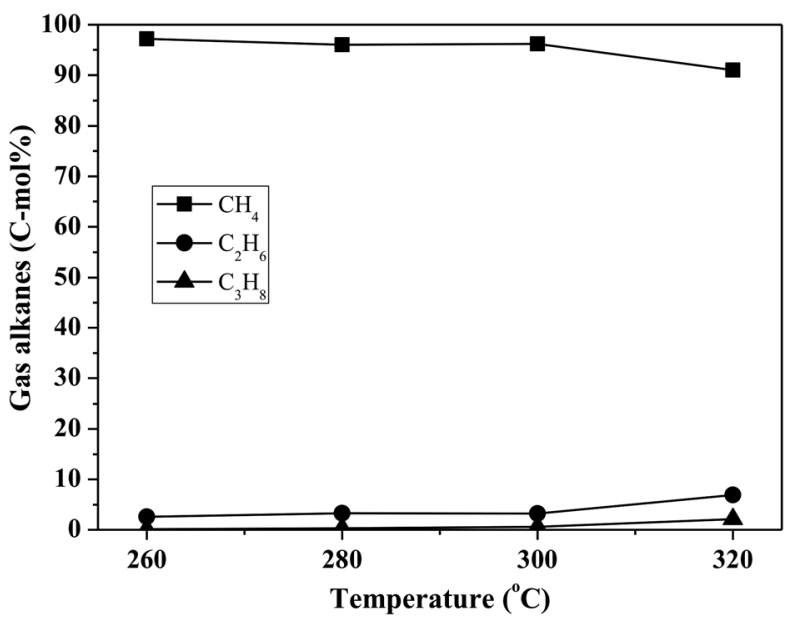

Fig. 7 The influence of reaction temperature on gas product distribution in FF-CP-FF hydrodeoxygenation. The reaction conditions are as stated for Fig. 6(a). 
Table 3 Functional groups in FF-CP-FF and in samples hydrogenated over $\mathrm{Pd} / \mathrm{C}$ at different temperatures, as determined by ${ }^{13} \mathrm{C} N M R$ analysis

\begin{tabular}{lllll}
\hline & $\mathrm{C}=\mathrm{O}(\%)$ & $\mathrm{C}=\mathrm{C}(\%)$ & $\mathrm{C}-\mathrm{O}(\%)$ & $\mathrm{C}-\mathrm{C}(\%)$ \\
\hline FF-CP-FF & 6.8 & 80.1 & 0 & 13.1 \\
Hydrogenation at $150{ }^{\circ} \mathrm{C}$ & 1.9 & 0.8 & 26.3 & 72.2 \\
Hydrogenation at $250{ }^{\circ} \mathrm{C}$ & 0 & 0 & 17.2 & 82.6 \\
Hydrogenation at $300{ }^{\circ} \mathrm{C}$ & 0 & 0 & 3.5 & 96.6
\end{tabular}

technique (Fig. S6 $\dagger$ ). The peaks at around $200 \mathrm{ppm}$, corresponding to $\mathrm{C}=\mathrm{O}$ bonds, had not disappeared, suggesting that the $\mathrm{C}=\mathrm{O}$ bonds in the FF-CP-FF were not efficiently hydrogenated into $\mathrm{C}-\mathrm{O}$ bonds. The peaks in the range of $100 \mathrm{ppm}$ to $170 \mathrm{ppm}$, which are associated with $\mathrm{C}=\mathrm{C}$ bonds, were greatly decreased, indicating the hydrogenation of $\mathrm{C}=\mathrm{C}$ bonds to $\mathrm{C}-\mathrm{C}$ bonds. For the products obtained at the higher temperature of $250{ }^{\circ} \mathrm{C}$, the peaks higher than $100 \mathrm{ppm}$ all disappeared, confirming the saturation of these $\mathrm{C}=\mathrm{C}$ and $\mathrm{C}=\mathrm{O}$ bonds into $\mathrm{C}-\mathrm{O}$ and $\mathrm{C}-\mathrm{C}$ bonds, respectively. The quantified analysis shown in Table 3 further demonstrated the sequential $\mathrm{C}=\mathrm{C}$ and $\mathrm{C}=\mathrm{O}$ bond hydrogenation. At the reaction temperature of $300{ }^{\circ} \mathrm{C}$, most of the oxygen was removed by cracking the $\mathrm{C}-\mathrm{O}$ bonds, with only $3.5 \%$ of $\mathrm{C}-\mathrm{O}$ bonds remaining in the final products. Introduction of solid acid promotes the dehydration of hydrogenation-derived $\mathrm{C}-\mathrm{OH}$, to produce the target products with high yields.

Fig. 8 shows the catalytic stability and regeneration performance of $\mathrm{Pd} / \mathrm{C}$ combined with $\mathrm{ZrP}$. The cyclic alkanes decreased from the initial $70 \%$ to a stable yield of $57 \%$ while simultaneously the light alkanes reduced from the initial $19 \%$ to below $10 \%$ during cycling. This decrease is due to a reduction in the acidic sites caused by $\mathrm{P}$ leaching in this hydrothermal hydrodeoxygenation according to our previous report. ${ }^{48}$ Considering that mixed $\mathrm{Pd} / \mathrm{C}$ and $\mathrm{ZrP}$ are hardly separable from each other,

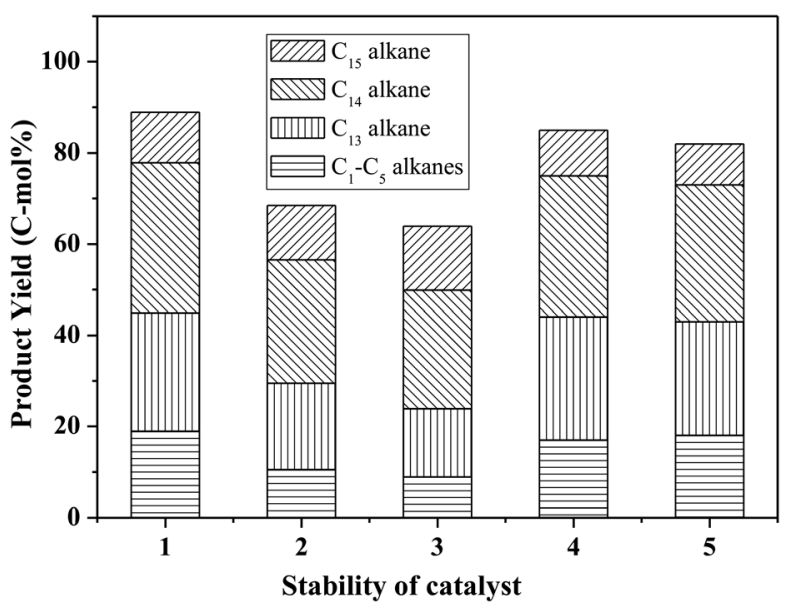

Fig. 8 Catalytic stability of $\mathrm{ZrP}$ and $\mathrm{Pd} / \mathrm{C}$ in the hydrodeoxygenation of FF-CP-FF to cyclic alkanes. Reaction conditions: $1.0 \mathrm{mmol} F F-C P-F F$, $15 \mathrm{~mL} \mathrm{H} \mathrm{H}_{2} \mathrm{O}, 0.05 \mathrm{~g} \mathrm{Pd} / \mathrm{C}, 0.10 \mathrm{~g} \mathrm{ZrP}, 4 \mathrm{MPa} \mathrm{H}_{2}$ pressure, $300^{\circ} \mathrm{C}, 3 \mathrm{~h}$. Bars $1-3$ show successive cycles, bar 4 represents the regenerated $\mathrm{ZrP}$ combined with fresh $\mathrm{Pd} / \mathrm{C}$ and bar 5 represents the regenerated $\mathrm{Pd} / \mathrm{C}$ combined with fresh $\mathrm{ZrP}$.

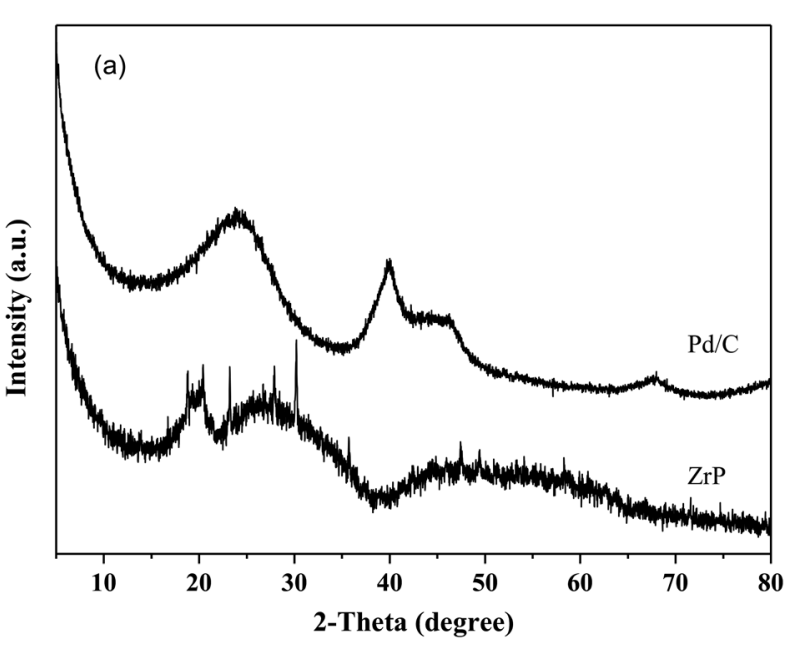

Fig. 9 XRD patterns of hydrothermally treated $\mathrm{ZrP}$ and $\mathrm{Pd} / \mathrm{C}$ followed by recalcination.

we simulated the catalyst regeneration by hydrothermal treatment of the individual $\mathrm{Pd} / \mathrm{C}$ and $\mathrm{ZrP}$ followed by recalcination according to the optimum reaction conditions. Interestingly, no matter which catalyst was regenerated, the activity of the combined catalyst could be recovered to the original level, demonstrating the excellent regeneration performance. After regeneration, the ZrP showed a similar amorphous nature to the fresh catalyst (Fig. 9). The weak and broad diffractions of the regenerated $\mathrm{Pd} / \mathrm{C}$ show that $\mathrm{Pd}$ particles were still highly dispersed on the carbon surface although their intensities were slightly higher than those in the fresh catalyst. The good retention of the physicochemical properties for both regenerated catalysts is the main reason for their excellent performance.

Hydrodeoxygenation of other aldol condensation intermediates (FF-CH-FF, HMF-CP-HMF, HMF-CH-HMF) were also investigated under the optimized reaction conditions by using

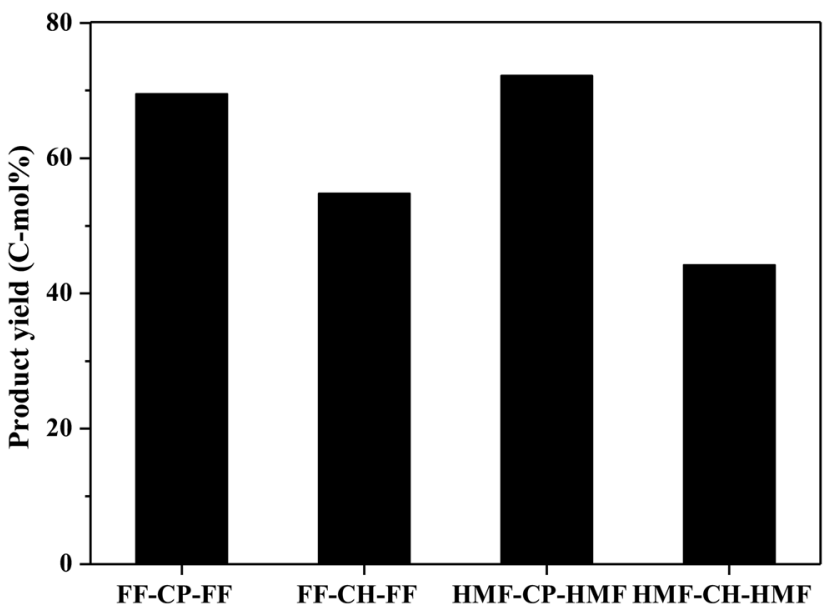

Fig. $10 \quad C_{13}-C_{18}$ cycloalkane production from various condensation intermediates. Reaction conditions: $1.0 \mathrm{mmol}$ condensation intermediates, $15 \mathrm{~mL} \mathrm{H} \mathrm{H}_{2} \mathrm{O}, 0.05 \mathrm{~g} \mathrm{Pd} / \mathrm{C}, 0.1 \mathrm{~g} \mathrm{ZrP}, 4 \mathrm{MPa} \mathrm{H}_{2}$ pressure, $300^{\circ} \mathrm{C}, 3 \mathrm{~h}$. 
$\mathrm{Pd} / \mathrm{C}$ combined with ZrP as the catalyst. Cycloalkanes with carbon chain lengths of between 13 and 18 were obtained. In the cases of FF-CH-FF and HMF-CP-HMF, 55\% and $72 \%$ yields, respectively, of cycloalkanes were obtained. When using HMF$\mathrm{CH}-\mathrm{HMF}$ as the feedstock, a $43 \%$ yield of cycloalkanes was obtained. This indicates that the developed catalyst of $\mathrm{Pd} / \mathrm{C}$ combined with ZrP is generally efficient for the production of jet fuel and/or diesel hydrocarbons by hydrodeoxygenation of these condensation intermediates (Fig. 10).

\section{Conclusions}

Long-chained cycloalkanes with carbon chain lengths of 13-18 were obtained from furfural species (FF and HMF) and cyclic ketones ( $\mathrm{CP}$ and $\mathrm{CH}$ ), all of which could be obtained from the renewable lignocellulosic biomass. The aldol condensation of the furfural species and cyclic ketones was conducted at $30{ }^{\circ} \mathrm{C}$ with a strong basic catalyst, to obtain over $90 \%$ yields of the desired condensation intermediates. The long-chained cycloalkanes with carbon chain lengths of 13-18 were produced via hydrodeoxygenation of the condensation intermediates at temperatures of $280-320{ }^{\circ} \mathrm{C}$ and times of $1-4 \mathrm{~h}$ by using a catalyst of $\mathrm{Pd} / \mathrm{C}$ combined with the solid acid ZrP. Under the optimized conditions, the highest yield of $76 \%$ of target products could be obtained. The combined catalyst showed reduced yields of cycloalkanes after the second and third cycles, but its performance could be largely recovered to its original level by hydrothermal treatment followed by recalcination of $\mathrm{Pd} / \mathrm{C}$ and $\mathrm{ZrP}$.

\section{Conflicts of interest}

There are no conflicts to declare.

\section{Acknowledgements}

The authors are grateful for the financial support from the Natural Science Foundation of China (51576199, 51536009 and 51376185) and the Natural Science Foundation of Guangdong Province (2017A030308010).

\section{References}

1 R. A. Sheldon, Green Chem., 2014, 16, 950.

2 M. J. Climent, A. Corma and S. Iborra, Green Chem., 2014, 16, 516.

3 N. Shi, Q. Y. Liu, Q. Zhang, T. J. Wang and L. L. Ma, Green Chem., 2013, 15, 1967.

4 Y. H. Liao, Q. Y. Liu, T. J. Wang, J. X. Long, L. L. Ma and Q. Zhang, Green Chem., 2014, 16, 3305.

5 Z. R. Zhang, J. L. Song and B. X. Han, Chem. Rev., 2017, 117, 6834.

6 F. Cheng and C. E. Brewer, Renewable Sustainable Energy Rev., 2017, 72, 673.

7 A. Bohre, S. Dutta, B. Saha and M. M. Abu-Omar, ACS Sustainable Chem. Eng., 2015, 3, 1263.
8 P. Y. Bi, J. C. Wang, Y. J. Zhang, P. W. Jiang, X. P. Wu, J. X. Liu, H. Xue, T. J. Wang and Q. X. Li, Bioresour. Technol., 2015, 183, 10.

9 J. P. Lange, E. van der Heide, J. van Buijtenen and R. Price, ChemSusChem, 2012, 5, 150.

10 J. Q. Bond, A. A. Upadhye, H. Olcay, G. A. Tompsett, J. Jae, R. Xing, D. M. Alonso, D. Wang, T. Y. Zhang, R. Kumar, A. Foster, S. M. Sen, C. T. Maravelias, R. Malina, S. R. H. Barrett, R. Lobo, C. E. Wyman, J. A. Dumesic and G. W. Huber, Energy Environ. Sci., 2014, 7, 1500.

11 C. R. Li, D. Q. Ding, Q. N. Xia, X. H. Liu and Y. Q. Wang, ChemSusChem, 2016, 9, 1712.

12 Y. P. Li, X. M. Huang, Q. Zhang, L. G. Chen, X. H. Zhang, T. J. Wang and L. L. Ma, Appl. Energy, 2015, 160, 990.

13 A. Bohre, B. Saha and M. M. Abu-Omar, ChemSusChem, 2015, 8, 4022 .

14 G. W. Huber, J. N. Chheda, C. J. Barrett and J. A. Dumesic, Science, 2005, 308, 1446.

15 L. Faba, E. Díaz and S. Ordóñez, ChemSusChem, 2014, 7, 2816.

16 M. X. Su, W. Z. Li, T. W. Zhang, H. S. Xin, S. Li, W. Fan and L. L. Ma, Catal. Sci. Technol., 2017, 7, 3555.

17 G. Y. Li, N. Li, S. S. Li, A. Q. Wang, Y. Cong, X. D. Wang and T. Zhang, Chem. Commun., 2013, 49, 5727.

18 G. Y. Li, N. Li, J. F. Yang, A. Q. Wang, X. D. Wang, Y. Cong and T. Zhang, Bioresour. Technol., 2013, 134, 66.

19 M. H. Chávez-Sifontes, M. E. Domine and S. Valencia, Catal. Today, 2015, 257, 305.

20 J. F. Yang, N. Li, G. Y. Li, W. T. Wang, A. Q. Wang, X. D. Wang, Y. Cong and T. Zhang, ChemSusChem, 2013, 6, 1149.

21 C. L. Cai, Q. Y. Liu, J. Tan, T. J. Wang, Q. Zhang and L. L. Ma, Korean Chem. Eng. Res., 2016, 54, 519.

22 J. Tan, Q. Y. Liu, C. L. Cai, S. B. Qiu, T. J. Wang, Q. Zhang, L. L. Ma and G. Y. Chen, RSC Adv., 2015, 5, 58784.

23 J. L. Xu, N. Li, X. F. Yang, G. Y. Li, A. Q. Wang, Y. Cong, X. D. Wang and T. Zhang, ACS Catal., 2017, 7, 5880.

24 A. Corma, O. de la Torre, M. Renz and N. Villandier, Angew. Chem., Int. Ed., 2011, 50, 2375.

25 A. Corma, O. de la Torre and M. Renz, ChemSusChem, 2011, 4, 1574.

26 G. Y. Li, N. Li, Z. Q. Wang, C. Z. Li, A. Q. Wang, X. D. Wang, Y. Cong and T. Zhang, ChemSusChem, 2012, 5, 1958.

27 M. Balakrishnan, E. R. Sacia and A. T. Bell, ChemSusChem, 2014, 7, 1078.

28 A. K. Misra and G. Agnihotri, Carbohydr. Res., 2004, 339, 1381.

29 G. Q. Xu, Q. Li, J. G. Feng, Q. Liu, Z. J. Zhang, X. C. Wang, X. Y. Zhang and X. D. Mu, ChemSusChem, 2014, 7, 105.

30 D. J. Liu and Y. X. E. Chen, ACS Catal., 2014, 4, 1302.

31 M. Mascal, S. Dutta and I. Gandarias, Angew. Chem., Int. Ed., 2014, 53, 1854.

32 J. Y. Xin, S. J. Zhang, D. X. Yan, O. Ayodele, X. M. Lu and J. J. Wang, Green Chem., 2014, 16, 3589.

33 G. Y. Li, N. Li, X. K. Wang, X. R. Sheng, S. S. Li, A. Q. Wang, Y. Cong, X. D. Wang and T. Zhang, Energy Fuels, 2014, 28, 5112. 
34 M. Hronec and K. Fulajtarova, Catal. Commun., 2012, 24, 100.

35 M. Hronec, K. Fulajtarova and T. Liptaj, Appl. Catal., A, 2012, 437, 104.

36 H. Z. Liu, T. Jiang, B. X. Han, S. G. Liang and Y. X. Zhou, Science, 2009, 326, 1250.

37 G. Y. Xu, J. H. Guo, Y. Zhang, Y. Fu, J. Z. Chen, L. L. Ma and Q. X. Guo, ChemCatChem, 2015, 7, 2485.

38 M. Hronec, K. Fulajtarova, T. Liptaj, M. Stolcova, N. Pronayova and T. Sotak, Biomass Bioenergy, 2014, 63, 291. 39 J. F. Yang, N. Li, G. Y. Li, W. T. Wang, A. Q. Wang, X. D. Wang, Y. Cong and T. Zhang, Chem. Commun., 2014, 50, 2572.

40 T. V. Bui, T. Sooknoi and D. E. Resasco, ChemSusChem, 2017, 10, 1631.

41 J. C. G. Da Silva, S. Folgueras-Dominguez and A. C. B. Dos Santos, J. Mater. Sci. Lett., 1999, 18, 197.
42 A. Sinhamahapatra, N. Sutradhar, B. Roy, P. Pal, H. C. Bajaj and A. B. Panda, Appl. Catal., B, 2011, 103, 378.

43 H. N. Kim, S. W. Keller, T. E. Mallouk, J. Schmitt and G. Decher, Chem. Mater., 1997, 9, 1414.

44 H. M. Gan, X. G. Zhao, B. N. Song, L. Guo, R. Zhang, C. Chen, J. Z. Chen, W. W. Zhu and Z. S. Hou, Chin. J. Catal., 2014, 35, 1148.

45 A. Sinhamahapatra, N. Sutradhar, B. Roy, A. Tarafdar, H. C. Bajaj and A. B. Panda, Appl. Catal., A, 2010, 385, 22.

46 J. T. Li, G. F. Chen, J. X. Wang and T. S. Li, Synth. Commun., 1999, 29, 965.

47 Y. B. Huang, Z. Yang, J. J. Dai, Q. X. Guo and Y. Fu, RSC Adv., 2012, 2, 11211.

48 Q. Y. Liu, T. Zhang, Y. H. Liao, C. L. Cai, J. Tan, T. J. Wang, S. B. Qiu, M. H. He and L. L. Ma, ACS Sustainable Chem. Eng., 2017, 5, 5940 . 